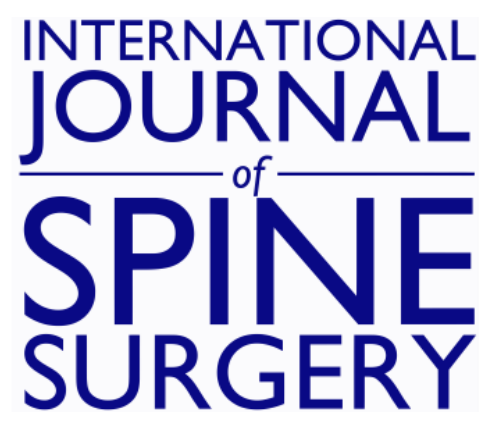

\title{
Feasibility of Endoscopic Inspection of Pedicle Wall Integrity in a Live Surgery Model
}

KRISTEN RADCLIFF, HARVEY SMITH, BOBBY KALANTAR, ROBERT ISAACS, BARRETT WOODS, ALEXANDER R. VACCARO and JAMES BRANNON

Int J Spine Surg 2018, 12 (2) 241-249

doi: https://doi.org/10.14444/5030

http://ijssurgery.com/content/12/2/241

This information is current as of April 26, 2023.

Email Alerts Receive free email-alerts when new articles cite this article. Sign up at: http://ijssurgery.com/alerts 


\title{
Feasibility of Endoscopic Inspection of Pedicle Wall Integrity in a Live Surgery Model
}

\author{
KRISTEN RADCLIFF, MD, ${ }^{1}$ HARVEY SMITH, MD, ${ }^{2}$ BOBBY KALANTAR, $\mathrm{MD},{ }^{3}$ ROBERT ISAACS, MD, ${ }^{4}$ \\ BARRETT WOODS, MD, ${ }^{1}$ ALEXANDER R. VACCARO, MD, PHD, MBA, ${ }^{1} \mathrm{JAMES} \mathrm{BRANNON,} \mathrm{MD}^{5}$ \\ ${ }^{I}$ Department of Orthopedic Surgery, Thomas Jefferson University, Rothman Institute, Egg Harbor, New Jersey, ${ }^{2}$ Department of Orthopedic Surgery, University of \\ Pennsylvania, Philadelphia, Pennsylvania, ${ }^{3}$ Department of Orthopedic Surgery, Georgetown University, Washington, DC, ${ }^{4}$ Department of Neurological Surgery, \\ Duke University, Durham, North Carolina, ${ }^{5}$ Orthopedic Sciences, Inc, Seal Beach, California, Joint Preservation Institute of Kansas, Overland Park, Kansas
}

\begin{abstract}
Background: Perforations of the pedicle wall during cannulation can occur with experienced surgeons. Direct endoscopic visualization has not been used to inspect pedicles previously due to bone bleeding obscuring the camera visualization. The hypothesis of this study was that endoscopic visualization of pedicle wall integrity was technically feasible and would enable identification of clinically significant pedicle breaches.

Methods: A live porcine model was used. Eight lumbar pedicles were cannulated. Clinically significant breaches were created. An endoscope was introduced and was used to inspect the pedicles.

Results: All lumbar pedicles were endoscopically visible at a systolic pressure of $100 \mathrm{~mm} \mathrm{Hg}$. Clinically relevant anatomic structures and iatrogenic pathology, such as medial, lateral, and anterior breaches, were identified. There were no untoward events resulting from endoscopic inspection of the pedicle endosteal canal.

Conclusions: Endoscopic inspection of lumbar pedicles was safe and effective. The findings on endoscopic inspection corresponded with the ball-tip probe palpation techniques. Additional techniques, such as selection between 2 tracts, was possible with the endoscopic technique.

Minimally Invasive Surgery

Keywords: endoscopic spine surgery, endoscopy, intraoosseous endoscopy, spine fusion, spine instrumentation, pedicle screws, pedicle cannulation, minimally invasive spine surgery
\end{abstract}

\section{INTRODUCTION}

Pedicle screws have revolutionized the treatment of spinal disorders. With screws, surgeons are able to immobilize and manipulate the spine in 3 dimensions. Pedicle screw instrumentation is the standard of care in the surgical management of degenerative scoliosis, degenerative spondylolisthesis, and trauma. To place pedicle screws, surgeons utilize handheld instruments to displace soft, cancellous bone within the pedicle whilst simultaneously preserving the external hard bony wall of cortical bone. The surgeon uses carefully defined anatomical landmarks and tactile feedback to create a screw tract through the cancellous bone of the pedicle. Once positioned, the screw position is often checked for encroachment upon spinal nerves by measuring the electrical conduction through triggered electromyography. Intact cortical walls create significant electrical impedance. ${ }^{1}$ Correctly placed pedicle screws will require higher amperage to detect electrical activity in adjacent spinal nerves. ${ }^{1}$ Other techniques, such as fluoroscopy ${ }^{2}$ or intraoperative computed tomography (CT) scan, ${ }^{3,4}$ are also used by some surgeons to guide or check screw placement.

Perforations of the outer cortical pedicle wall can occur $^{5}$ using manual freehand techniques, ${ }^{6}$ fluoroscopy, ${ }^{2,7}$ and even intraoperative $\mathrm{CT}^{3}$ Perforation rates as high as $30 \%$ have been reported in some studies. ${ }^{8}$ Pedicle screw malposition can result in unanticipated readmission and reoperation, ${ }^{9-11} \mathrm{du}-$ ral laceration, ${ }^{12}$ nerve injury, ${ }^{13-17}$ pedicle fractures, ${ }^{17,18}$ and vascular injury. ${ }^{19,20}$

Direct visualization of the cannulated bony channel would provide valuable information to confirm accurate trajectory of the tract and documentation for the medical record confirming the absence of a cortical wall breach. Furthermore, if a cortical wall breach is observed endoscopically, a handheld ball-tip probe can be used to palpate the direct area of concern versus complete reliance of proprioception and blind palpation. Endoscopy has revolutionized visibility of other hard-to-see loca- 
tions within the body such as the knee, shoulder, and abdomen. Endoscopic visualization is superior to traditional open surgery that relies on line-ofsight vision in many cases. However, endoscopy has not been widely used in the placement of spinal instrumentation due to resident bleeding within the pedicle obscuring visualization, the small diameter in which visualization must occur, and the inability to exploit the unique property difference between a Newtonian fluid (water) and non-Newtonian fluid (blood). ${ }^{21-24}$

Recently, an endoscopic instrument was developed to facilitate endoscopic inspection of the internal pedicle channel. The hypothesis of this study was that endoscopic visualization of pedicle wall integrity is technically feasible and will enable identification of clinically significant pedicle breaches.

\section{METHODS}

\section{Overview}

One skeletally mature female pig (approximately $82 \mathrm{~kg}$ ) underwent posterior lumbar exposure and pedicle cannulation followed by endoscopic verification of pedicle wall integrity. The investigation was performed using an approved Institutional Animal Care and Use Committee protocol at an accredited facility. The investigators were 2 orthopedic surgeons with familiarity in intraoosseous endoscopy and spine surgery.

\section{Surgical Procedure}

General anesthesia was induced. The animal was anesthetized according to veterinarian's protocol. An endotracheal tube was attached to an anesthesia machine. Replacement fluids $(0.9 \% \mathrm{NaCl})$ were administered via the intravenous catheter. An area on the abdomen was shaved to accommodate an electrode return patch. The animal was placed prone on the surgical table. The area around the lumbar spine was shaved, prepped, and draped in preparation for surgery. Normal systolic and diastolic blood pressure was maintained throughout the procedure (mean arterial pressure 70). An arterial line monitor was used to monitor blood pressure.

Midline, posterior open dissection was performed through the skin and subcutaneous tissues on the posterior lumbar spine at the level of the iliac crests. Subperiosteal exposure of the spinous processes, laminae, facets, and transverse processes was performed. Meticulous hemostasis was obtained.
The pedicles were then cannulated in the usual fashion. The upslope of the transverse process onto the superior articular process was identified. The intersection of a horizontal line through the midpoint of the transverse process and the lateral border of the facet was considered the starting point of the pedicle screws. The starting point was decorticated with a rongeur. The pedicle was entered with a curved, tapered gearshift with pronosupination in the usual fashion. When necessary, a radiograph was taken to confirm the trajectory and spinal level. The pedicles were cannulated 35 $\mathrm{mm}$ according to the depth on the gearshift. The pedicles were entered $35 \mathrm{~mm}$ according to the depth on the gearshift. Eight holes were made in the spine with an attempt to establish correct pedicle canal holes as well as to breach pedicle canals.

Following cannulation, the inner aspect of the pedicles was palpated with a ball-tipped probe as carefully as possible. A consensus was reached between the investigators about whether the pedicle was intact or breached. If a breach was suspected, the direction was also reported.

\section{Endoscopic Pedicle Inspection}

The endoscopic instrument's outer trochar was connected to normal saline irrigation in 3 -L bags. The endoscopic instrument uses common endoscopy monitors available in most hospitals. No epinephrine was present in the normal saline bags. The endoscopic instrument (with inner stylette and outer trochar together) was then placed into the pedicle tract. Saline was allowed to flow at gravity pressure. No specialized pumps or pressure bags were used. The inner stylette, which has a diameter of $3.2 \mathrm{~mm}$, was removed. A $3.0-\mathrm{mm}$ endoscope was then introduced into each pedicle. The pedicle wall was inspected with a 0-degree and a 30-degree endoscope.

Breaches were deliberately made in the medial wall, anterior vertebral body, and lateral muscle tissue. The breaches were confirmed by palpation with a ball-tip probe.

The endoscopic instrument was used to inspect the pedicle walls and confirm the breach locations.

\section{RESULTS}

\section{Feasibility}

Eight pedicles were cannulated in total in L6, L5, L4, and L3. All $(8 / 8)$ of the pedicles were 

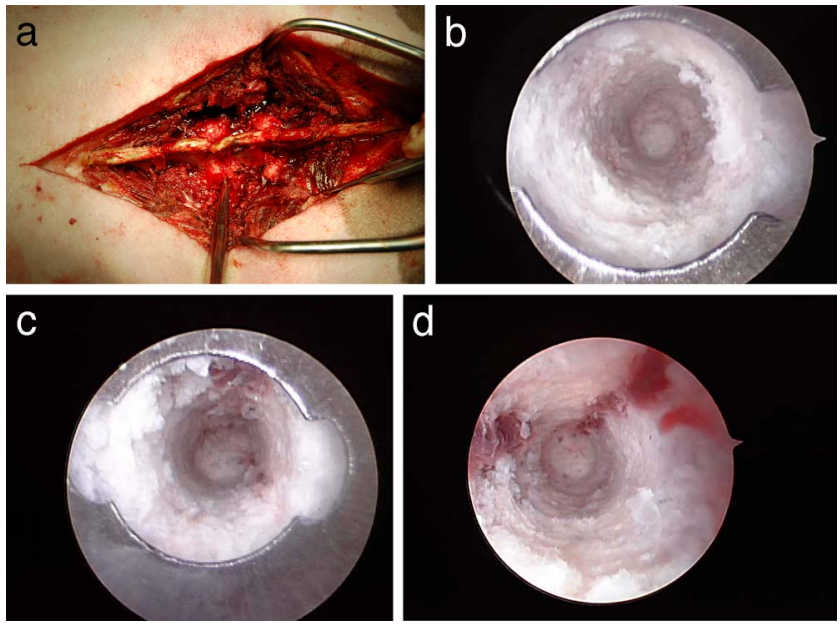

Figure 1. (a) Photograph of the instrument in the wound while visualization was being performed. The instrument is visible adjacent to the lumbar facet joints. Cranial is to the left and caudal is to the right. There was only trace fluid extravasation of irrigation from into the wound. The endoscopic instrument is designed to achieve a seal with the endosteal pedicle surface. (b) Endoscopic view of an intact pedicle. The distal tip of the cannula with batwing indentation to determine orientation is visible. A complete tube of ivory bone is visible through the cannula. Medial is to the right side of the screen. (c) Endoscopic view of an intact pedicle. A complete tube of white bone is visible through the cannula. At the 12 o'clock position, red, cancellous bone is visible. (d) Endoscopic view of an intact pedicle. A complete tube of white bone is visible through the cannula. At the 1 o'clock and 9 o'clock positions, red, cancellous bone and marrow are visible.

successfully visualized with the endoscopic instrument. The internal blood within the pedicles was cleared immediately once the endoscopic instrument was seated within the pedicle and irrigation was commenced. There were no pedicles $(0 / 8)$ that were not able to be studied due to bleeding. Complete examination of the interior of each pedicle from posterior to anterior could be accomplished within 1 minute.

\section{Comparison to Manual Palpation}

Using both the 0 -degree scope and the 30-degree scope, the medial, lateral, superior, and inferior walls and the floor were visualized on all pedicles (Figure
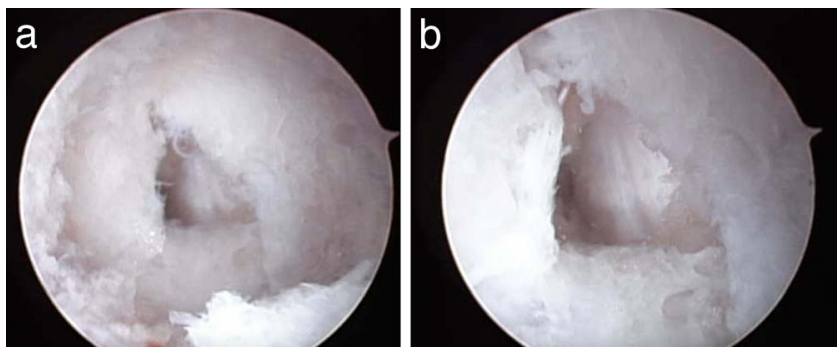

Figure 2. (a) Endoscopic view of a medial pedicle wall breach into the spinal canal. The triangular breach was deliberately created with a gearshift. Within the breach linear vertical fragments of ligamentum flavum are visible. (b) Close-up view of the medial pedicle breach. At approximately 4 o'clock yellow epidural fat is visible in the defect.
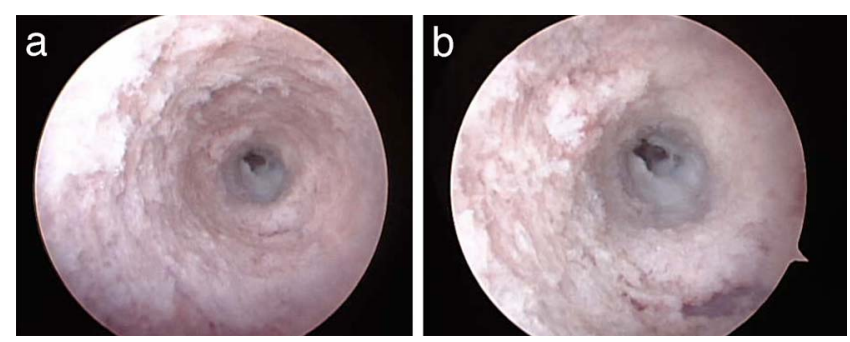

Figure 3. (a) Endoscopic view of anterior pedicle breach. The pedicle side walls display ivory cortical bone. The white anterior longitudinal ligament is visible in the center of the screen. It is lighter colored than the adjacent, ivory colored bone. There is a square-shared defect in the anterior longitudinal ligament. (b) Close-up view of the anterior pedicle breach. The white anterior longitudinal ligament and anterior defect are visible. The surrounding bone walls are intact.

1, Supplemental Videos 1A and 1B; http://www.ijs surgery.com/lookup/suppl/doi:10.14444/5030/-/ DC1/videola.mp4; http://www.ijssurgery.com/look up/suppl/doi:10.14444/5030/-/DC1/video1b.mp4). The visualized pedicle wall integrity corresponded in all cases ( $8 / 8$ pedicles) to the investigator's assessment with ball-tip probe. The 30-degree scope was used in 4 pedicles. The major difference during endoscopic visualization between a 0 -degree scope and a 30-degree scope is that a more direct view of the endosteal surface is achieved with a 30 -degree scope. This may be relevant when a more direct view of a breach is required when determining the significance of a breach.

\section{Identification of Breaches}

Breaches were deliberately made using the curved gearshift in the pedicles medially $(\mathrm{n}=2)$, laterally $(\mathrm{n}=2)$, and anteriorly $(\mathrm{n}=2)$. Perforations of the pedicular walls were easily identified with the endoscope in all 6 cases. Medially, the exposed dura and epidural fat could be visualized (Figure 2, Supplemental Videos 2A and 2B; http://www.ijs surgery.com/lookup/suppl/doi:10.14444/5030/-/
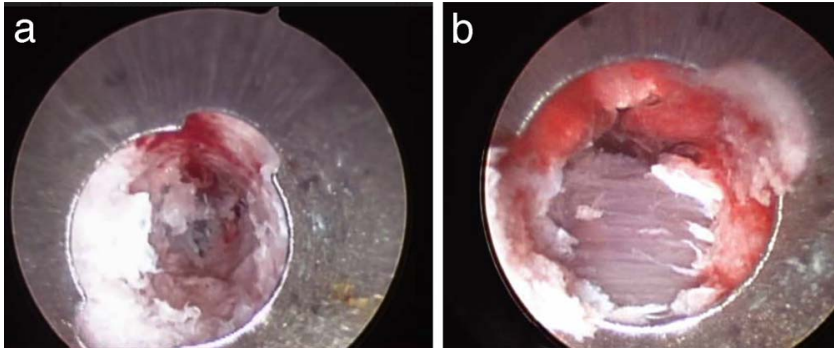

Figure 4. (a) Endoscopic view of lateral pedicle wall breach. In the center-left of the field there are purple horizontal fibers of paraspinous muscles. (b) Closeup view of lateral pedicle wall breach. The horizontal muscle fibers are visible through the defect. 

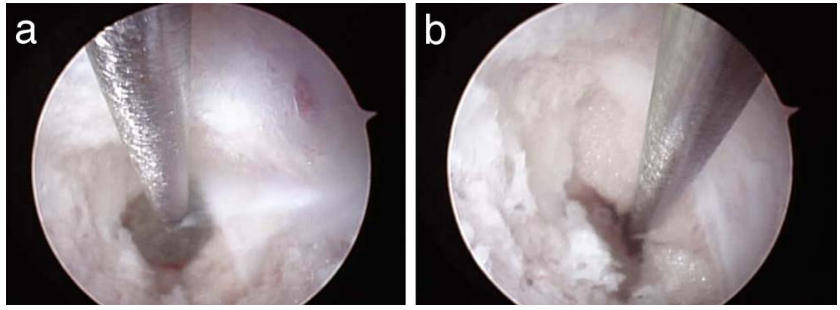

Figure 5. (a) Endoscopic view with ball-tip probe inside of the pedicle. The endoscopic instrument is alongside the ball-tip probe. The ball is adjacent to a defect in the medial pedicle wall. Epidural fat is distal to the tip of the ball. Ligamentum flavum is to the right side of the ball. (b) Probing the spinal canal defect. The ball-tip probe has been advanced under endoscopic guidance into the spinal canal outside of the pedicle. Epidural fat is adjacent to the shaft of the probe. The ligamentum flavum has been reflected laterally.

DC1/video2a.mp4; http://www.ijssurgery.com/look up/suppl/doi:10.14444/5030/-/DC1/video2b.mp4). Perforation of the anterior vertebral body was also easily visualized (Figure 3, Supplemental Video 3; http://www.ijssurgery.com/lookup/suppl/doi:10. 14444/5030/-/DC1/video3.mp4) showing the anterior longitudinal ligament. Lateral perforation was also visualized, showing paraspinous muscles (Figure 4, Supplemental Videos 4A and 4B; http://www. ijssurgery.com/lookup/suppl/doi:10.14444/5030/-/ DC1/video4a.mp4; http://www.ijssurgery.com/look up/suppl/doi:10.14444/5030/-/DC1/video4b.mp4).

\section{Combination with Other Techniques}

The endoscopic instrument was used in combination with a ball-tip probe to visualize the defect into which the ball-tip probe was subsiding (Figure 5, Supplemental Video 5; http://www.ijssurgery.com/ lookup/suppl/doi:10.14444/5030/-/DC1/video5. mp4). A guidewire was introduced into a pedicle and the endoscopic instrument was used to document the position of the guidewire (Figure 6, Supplemental Video 6; http://www.ijssurgery.com/lookup/suppl/ doi:10.14444/5030/-/DC1/video6.mp4). One pedicle

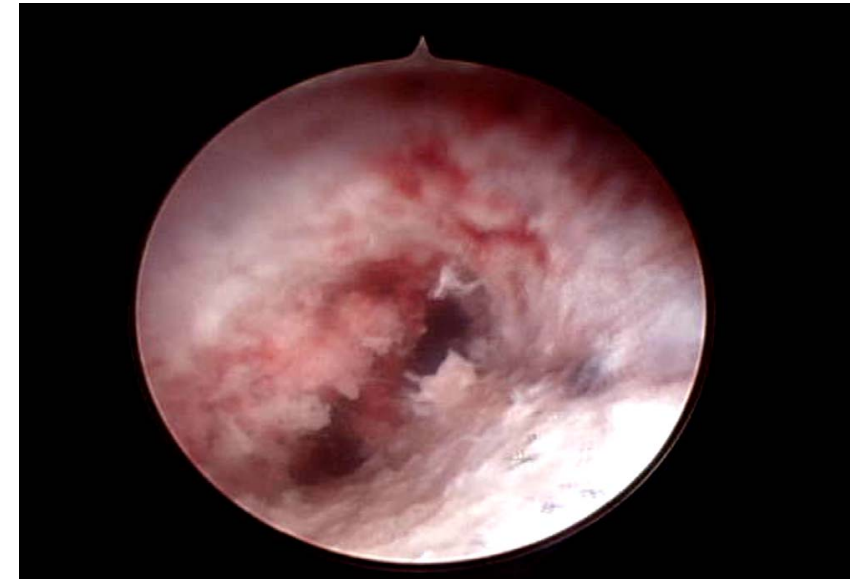

Figure 7. Endoscopic view of a pedicle with 2 divergent paths. One path is at approximately 2 o'clock and one path is at 7 o'clock.

was cannulated twice from the same starting point to create 2 trajectories. The endoscopic instrument was used to identify and explore dual paths in a lumbar pedicle (Figure 7, Supplemental Video 7; http://www.ijssurgery.com/lookup/suppl/doi:10. 14444/5030/-/DC1/video7.mp4).

\section{Fluid Extravasation}

There was no significant extravasation of fluid into the spinal canal. There was no thecal sac compression visualized or nerve root compression visualized due to irrigation fluid. Once the irrigation was ceased, there was no retrograde flow of irrigation fluid from the extraosseus structures into the pedicles. There was no significant soft tissue swelling on breached cases. In 2 instances, irrigation was deliberately stopped. When irrigation was stopped, blood flow from the pedicle walls resumed immediately. (Figure 8, Supplemental Videos 8A and $8 \mathrm{~B}$; http://www.ijssurgery.com/lookup/suppl/ doi:10.14444/5030/-/DC1/video8a.mp4; http://www.
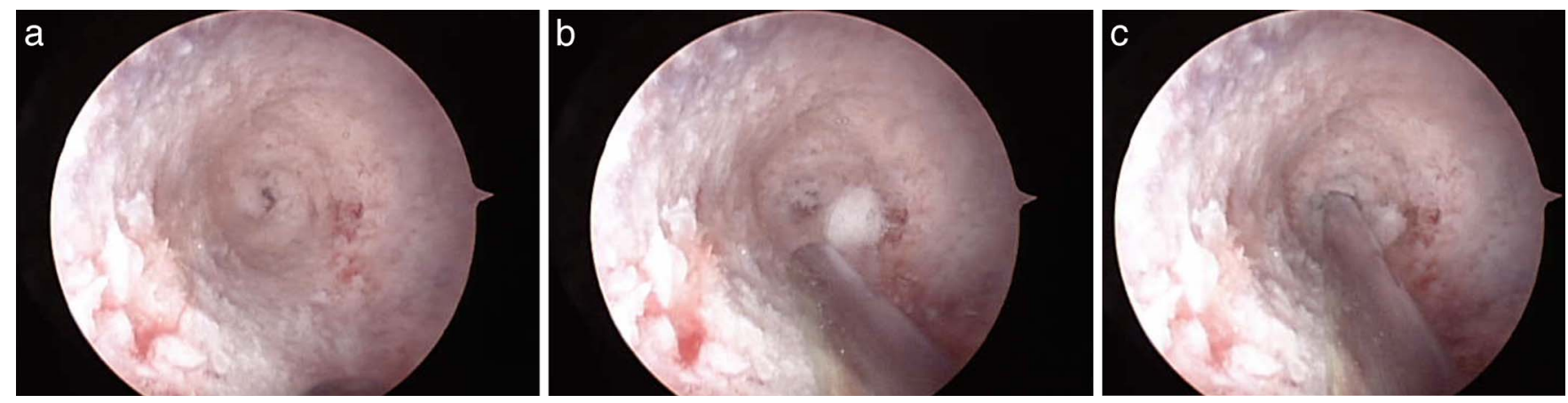

Figure 6. (a) Endoscopic view with anterior defect in the center of the field. The remainder of the pedicle walls are intact. (b) Endoscopic view with anterior defect in the center of the field. A guidewire is being advanced alongside the endoscopic instrument at the 6 o'clock position. (c) Guidewire placed into the anterior vertebral body defect under endoscopic guidance. 

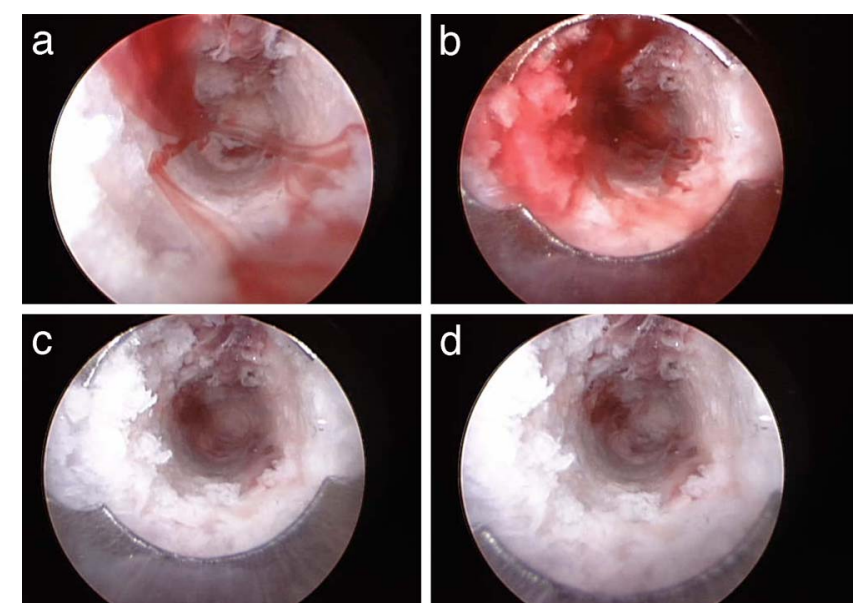

Figure 8. (a) Endoscopic view of a pedicle with intact walls (Figure 1b) immediately after irrigation fluid was stopped. Bony bleeding resumed immediately. The bleeding appears to have formed linear, ribbon-shaped lamellae. (b) Endoscopic view of a pedicle with intact walls with bleeding allowed to continue further. Blood filled the entire inner aspect of the pedicle. (c) Endoscopic view of pedicle with irrigation reestablished. The blood began to clear. (d) Endoscopic view of pedicle with irrigation reestablished. The blood cleared easily.

ijssurgery.com/lookup/suppl/doi:10.14444/5030/-/ DC1/video8b.mp4). The blood was then quickly cleared with a resumption of irrigation (Figure 8, Videos $8 \mathrm{~A}$ and $8 \mathrm{~B}$; http://www.ijssurgery.com/look up/suppl/doi:10.14444/5030/-/DC1/video8a.mp4; http://www.ijssurgery.com/lookup/suppl/doi:10. 14444/5030/-/DC1/video8b.mp4).

\section{DISCUSSION}

Safe placement of spinal instrumentation is of paramount importance in overall successful spinal surgery. These results indicate that low-pressure endoscopic inspection is technically feasible in a live animal model. Endoscopy provided valuable information about anatomical defects and guidewire placement in an efficient manner. There were no complications directly identified from the endoscopic technique. There were no specialized anesthetic requirements from the endoscopic technique.

Current techniques to verify pedicle screw placement are not universally accurate or effective. Manual pedicle palpation with a ball-tip probe has low accuracy ${ }^{25,26}$ and the potential for inadvertent neurological injury with the probe. ${ }^{27}$ Even stereotactic image guidance cannot entirely prevent pedicle perforations. ${ }^{28}$ Electrical neuromonitoring adds cost and time to surgical procedures. In some circumstances, neuromonitoring can fail to identify a pedicle screw breach. ${ }^{29,30}$ False-positive alerts can also occur with neuromonitoring, requiring addi- tional operative time and steps. A recent systematic review concluded "There is no evidence to date that IOM [intraoperative neurological monitoring] can prevent injury to the nerve roots. Unfortunately, once a nerve root injury has taken place, changing the direction of the screw does not alter the outcome." ${ }^{1}$ Other pressure- and electrical conduction-based techniques to verify pedicle accuracy, such as specialized piezoelectric piercer probes, can also lead to misplaced pedicle screws ${ }^{31}$ and can result in false-negative errors. ${ }^{32,33}$ Other emerging techniques such as intraosseous ultrasound, ${ }^{34-39}$ robotic guidance, or near-infrared spectroscopy, require substantial equipment and are not without false-negative errors. ${ }^{40,41}$

To our knowledge, our study is the first to report successful endoscopic visualization of the internal aspect of a lumbar pedicle with low-flow irrigation. Endoscopy has been extensively used in other areas of surgery to minimize exposure. Current endoscopic spine techniques include foraminal discectomy or decompression techniques, but endoscopic instrumentation and fusion has not been widely performed due to technical challenges. Most previous descriptions of endoscopic pedicle screw instrumentation have focused on endoscopic soft tissue dissection, endoscopic identification of screw starting points, and endoscopic placement of rods. ${ }^{21-23}$ In the aforementioned studies, there is no description of inserting the endoscope into the pedicles to inspect the wall integrity. ${ }^{2-23}$

There are a few studies that describe visualization of the intraosseous anatomy of the lumbar pedicles with high-flow irrigation. ${ }^{24,42,43}$ However, in contrast to the current technique, the authors of these studies describe high-pressure irrigation. Essentially the endoscope is continually flushing away active bleeding in an open system. In our study, the unique design of the endoscopic instrument exploits the differing fluid properties between Newtonian and non-Newtonian fluids, thereby producing crystalclear images so that relevant anatomy can be viewed and documented. Figure 8 illustrates laminar streaks of blood (non-Newtonian fluid) flowing through the saline medium. Such laminar flow requires that the saline (a Newtonian fluid) within the pedicle is otherwise motionless. Thus the endoscopic instrument seals the pedicle channel, prevents fluid from escaping from the pedicle, and creates a closed system. If the saline were flowing in a high-pressure environment, it would disrupt the 
laminations and thus turn the image cloudy. The current endoscopic instrument, through the attached fluid column, equilibrates the systolic pressure with only a minimal volume of saline in an intact pedicle. Therefore, minimal or low-pressure irrigation is all that is necessary for successful instrumentation. High-flow irrigation could create complications such as edema, neural element compression, or compartment syndrome. Highpressure lumbar irrigation has been demonstrated to increase cervical epidural pressure and possibly lead to intracranial hypertension. ${ }^{44}$

In our study, clinically relevant breaches were identified. These breaches were confirmed by manual palpation under direct endoscopic visualization. In this manner, even the palpation with a ball-tip probe under direct visualization was more controlled and perhaps less likely to cause inadvertent neurological injury. There were no complications from the usage of the endoscopic technique. Furthermore, the time per pedicle was approximately 1 minute. Once the endoscopic instrument was seated within the pedicle, the entire intraosseous space was sealed. Therefore only a minimal pressure was needed to cease blood flow and in fact to create retrograde flow. The animal's blood pressure was normal. No abnormal hemodynamic conditions were necessary, such as severe hypotension to reduce bony bleeding.

Limitations of the current study include the use of a porcine model. However, porcine models have been used in spine surgery previously for feasibility studies. ${ }^{41,45-53}$ Additional studies by other, nonconflicted, investigators are needed. Other limitations include the small number of pedicles tested. In contrast to previous studies, threads were not tapped into the pedicles in this study ${ }^{24}$ because many modern pedicle screw systems are now deemed "self-tapping." Therefore, the experimental conditions were designed to simulate the current surgical technique. Another limitation is that actual pedicle screws were not placed in this study. We acknowledge that there is potential that pedicles could be correctly cannulated but that errant screws could be placed due to misdirection after cannulation. However, the purpose of this study was to enhance the ability to identify a correctly cannulated tract. Despite the assistive techniques currently available, pedicle screw revision is one of the leading causes of reoperation after spine surgery, particularly in the hyperacute postoperative period. ${ }^{10,11}$
The main advantage of using an endoscopic technique for lumbar pedicle trajectories is the direct visualization of pedicle wall integrity. This feature lends itself readily to photographic and video documentation and education of trainees. In a recent cadaveric study, a pedicle breach rate of $51 \%$ was reported with resident physicians attempting to cannulate thoracic pedicles. ${ }^{54}$ The endoscopic instrument does not require any special setup, placement of needles or electrodes into the patients, alternative anesthetic techniques, monitoring equipment, special training, a change in technique, or capital expenditures. The endoscopic instrument allows the surgeon to visually identify cortical breaches before compression and neurological injury by screws occur. The endoscopic instrument does not employ any ionizing radiation. An additional advantage is that the endoscopic instrument continuously irrigates the pedicles with an antibiotic solution of the surgeon's choice, and may thereby reduce the risk of surgical site infection. Other indirect techniques, such as electrical stimulation, have been associated with false-positive and false-negative errors. Electrical stimulation, the most widely used method to check pedicle screw placement, also requires specialized anesthetic technique involving the absence of chemical paralysis. The endoscopic technique is versatile and similar to an open technique, which allows surgeons a smoother learning curve. Importantly, if a treating surgeon continues to observe breaches, with the added benefit of the location of the breach, he/she could then make real-time adjustments to the technique used to cannulate the pedicle as a way of improving patient safety. There is no ionizing radiation in the endoscopic technique. Further developments in endoscopic imaging and fusion techniques will help refine this procedure. Currently, the screw system does not permit full endoscopic placement of longitudinal connecting rods. Additionally, the technique is diagnostic only. The system does not currently incorporate endoscopic "drilling" features to cannulate a pedicle. Ultimately, we believe that endoscopically assisted posterolateral lumbar instrumentation will reduce perioperative complications, costs, and the risk of return to the operating room.

\section{REFERENCES}

1. Sharan A, Groff MW, Dailey AT, et al. Guideline update for the performance of fusion procedures for degener- 
ative disease of the lumbar spine. Part 15: electrophysiological monitoring and lumbar fusion. $J$ Neurosurg Spine. 2014;21(1):102-105.

2. Schizas C, Michel J, Kosmopoulos V, Theumann N. Computer tomography assessment of pedicle screw insertion in percutaneous posterior transpedicular stabilization. Eur Spine J. 2007;16(5):613-617.

3. Mason A, Paulsen R, Babuska JM, et al. The accuracy of pedicle screw placement using intraoperative image guidance systems. J Neurosurg Spine. 2014;20(2):196-203.

4. Hahn P, Oezdemir S, Komp M, et al. Navigation of pedicle screws in the thoracic spine with a new electromagnetic navigation system: a human cadaver study. BioMed Res Int. 2015;2015:183586.

5. Sugawara R, Tsuji T, Saito T, Nohara A, Kawakami K, Kawakami N. Medially misplaced pedicle screws in patients without neurological deficits following scoliosis surgery: to observe or to remove? Eur Spine J. 2015;24(7):1450-1456.

6. Karapinar L, Erel N, Ozturk H, Altay T, Kaya A. Pedicle screw placement with a free hand technique in thoracolumbar spine: is it safe? J. Spinal Disord Tech. 2008;21(1):63-67.

7. Koktekir E, Ceylan D, Tatarli N, Karabagli H, Recber F, Akdemir G. Accuracy of fluoroscopically-assisted pedicle screw placement: analysis of 1,218 screws in 198 patients. Spine J. 2014;14(8):1702-1708.

8. Modi H, Suh SW, Song HR, Yang JH. Accuracy of thoracic pedicle screw placement in scoliosis using the ideal pedicle entry point during the freehand technique. Int Orthop. 2009;33(2):469-475.

9. Samdani AF, Belin EJ, Bennett JT, et al. Unplanned return to the operating room in patients with adolescent idiopathic scoliosis: are we doing better with pedicle screws? Spine (Phila Pa 1976). 2013;38(21):1842-1847.

10. Al-Khouja L, Shweikeh F, Pashman R, Johnson JP, Kim TT, Drazin D. Economics of image guidance and navigation in spine surgery. Surg Neurol Int. 2015;6(Suppl 10):S323-326.

11. Shimizu T, Fujibayashi S, Takemoto M, Otsuki B, Kimura H, Ota M, et al. A multi-center study of reoperations within 30 days of spine surgery. Eur Spine J. 2016;25(3):828835 .

12. Feng B, Shen J, Zhang J, Zhou X, Liang J, Qiu G. How to deal with cerebrospinal fluid leak during pedicle screw fixation in spinal deformities surgery with intraoperative neuromonitoring change. Spine (Phila Pa 1976). 2014;39(1):E20-25.

13. Papin P, Arlet V, Marchesi D, Rosenblatt B, Aebi M. Unusual presentation of spinal cord compression related to misplaced pedicle screws in thoracic scoliosis. Eur Spine J. 1999;8(2):156-159.

14. Modi HN, Suh SW, Yang JH, Yoon JY. False-negative transcranial motor-evoked potentials during scoliosis surgery causing paralysis: a case report with literature review. Spine (Phila Pa 1976). 2009;34(24):E896-E900.

15. Dede O, Ward WT, Bosch P, Bowles AJ, Roach JW. Using the freehand pedicle screw placement technique in adolescent idiopathic scoliosis surgery: what is the incidence of neurological symptoms secondary to misplaced screws? Spine (Phila Pa 1976). 2014;39(4):286-290.

16. Mac-Thiong JM, Parent S, Poitras B, Joncas J, Hubert
L. Neurological outcome and management of pedicle screws misplaced totally within the spinal canal. Spine (Phila $\mathrm{Pa}$ 1976). 2013;38(3):229-237.

17. Suk SI, Kim WJ, Lee SM, Kim JH, Chung ER. Thoracic pedicle screw fixation in spinal deformities: are they really safe? Spine (Phila Pa 1976). 2001;26(18):2049-2057.

18. Amato V, Giannachi L, Irace C, Corona C. Accuracy of pedicle screw placement in the lumbosacral spine using conventional technique: computed tomography postoperative assessment in 102 consecutive patients. J Neurosurg Spine. 2010;12(3):306-313.

19. Potter MQ, Lawrence BD, Kinikini DV, Brodke DS. Periaortic pedicle screw removal with endovascular control of the aorta and intraoperative aortography: a case report and review of the literature. Evidence-Based Spine-Care J. 2013;4(2):149-153.

20. Parker SL, Amin AG, Santiago-Dieppa D, et al. Incidence and clinical significance of vascular encroachment resulting from freehand placement of pedicle screws in the thoracic and lumbar spine: analysis of 6816 consecutive screws. Spine (Phila Pa 1976). 2014;39(8):683-687.

21. Jahng TA, Fu TS, Kim DH. Open versus endoscopic lumbar pedicle screw fixation and posterolateral fusion in a sheep model: a feasibility study. Spine J. 2004;4(5):519-526.

22. Muller A, Gall C, Marz U, Reulen HJ. A keyhole approach for endoscopically assisted pedicle screw fixation in lumbar spine instability. Neurosurgery. 2000;47(1):85-95; discussion 96.

23. Osman SG. Endoscopic transforaminal decompression, interbody fusion, and percutaneous pedicle screw implantation of the lumbar spine: a case series report. Int J Spine Surg. 2012;6:157-166.

24. Stauber MH, Bassett GS. Pedicle screw placement with intraosseous endoscopy. Spine. 1994;19(1):57-61.

25. Donohue ML, Moquin RR, Singla A, Calancie B. Is in vivo manual palpation for thoracic pedicle screw instrumentation reliable? J Neurosurg Spine. 2014;20(5):492-496.

26. Watanabe K, Matsumoto M, Tsuji T, et al. Ball tip technique for thoracic pedicle screw placement in patients with adolescent idiopathic scoliosis. J Neurosurg Spine. 2010;13(2):246-252.

27. Sedory DM, Crawford JJ, Topp RF. The reliability of the ball-tipped probe for detecting pedicle screw tract violations prior to instrumenting the thoracic and lumbar spine. Spine (Phila Pa 1976). 2011;36(6):E447-E453.

28. Hart RA, Hansen BL, Shea M, Hsu F, Anderson GJ. Pedicle screw placement in the thoracic spine: a comparison of image-guided and manual techniques in cadavers. Spine. 2005;30(12):E326-E331.

29. Danesh-Clough T, Taylor P, Hodgson B, Walton M. The use of evoked EMG in detecting misplaced thoracolumbar pedicle screws. Spine (Phila Pa 1976). 2001;26(12):1313-1316.

30. Wang MY, Pineiro G, Mummaneni PV. Stimulusevoked electromyography testing of percutaneous pedicle screws for the detection of pedicle breaches: a clinical study of 409 screws in 93 patients. J Neurosurg Spine. 2010;13(5):600 605.

31. Chaput CD, George K, Samdani AF, Williams JI, Gaughan J, Betz RR. Reduction in radiation (fluoroscopy) while maintaining safe placement of pedicle screws during 
lumbar spine fusion. Spine (Phila Pa 1976). 2012;37(21):E1305E1309.

32. Guillen PT, Knopper RG, Kroger J, Wycliffe ND, Danisa OA, Cheng WK. Independent assessment of a new pedicle probe and its ability to detect pedicle breach: a cadaveric study. J Neurosurg Spine. 2014;21(5):821-825.

33. Bin L, Yong $\mathrm{H}$, Yang $\mathrm{X}$, Bi Z, Mo S, Zhi-Min G. Pedicle screw piercer with warning device - a technique to increase accuracy of pedicle screw placement: a cadaveric study. Indian J Orthop. 2014;48(6):545-549.

34. Kantelhardt SR, Bock CH, Larsen J, et al. Intraosseous ultrasound in the placement of pedicle screws in the lumbar spine. Spine (Phila Pa 1976). 2009;34(4):400-407.

35. Kantelhardt SR, Larsen J, Bockermann V, Schillinger W, Giese A, Rohde V. Intraosseous ultrasonography to determine the accuracy of drill hole positioning prior to the placement of pedicle screws: an experimental study. J Neurosurg Spine. 2009;11(6):673-680.

36. Chen Z, Wu B, Zhai X, et al. Basic study for ultrasound-based navigation for pedicle screw insertion using transmission and backscattered methods. PloS One. 2015;10(4):e0122392.

37. Ungi T, Moult E, Schwab JH, Fichtinger G. Tracked ultrasound snapshots in percutaneous pedicle screw placement navigation: a feasibility study. Clin Orthop Related Res. 2013;471(12):4047-4055.

38. Raphael DT, Chang JH, Zhang YP, Kudija D, Chen TC, Shung KK. A-Mode ultrasound guidance for pedicle screw advancement in ovine vertebral bodies. Spine J. 2010;10(5):422432.

39. Kantelhardt SR, Bock HC, Siam L, et al. Intra-osseous ultrasound for pedicle screw positioning in the subaxial cervical spine: an experimental study. Acta Neurochirurgica. 2010;152(4):655-661.

40. Liu Y, Wang Y, Qian Z, Zhao J, Cao X, Li W. Monitoring the reduced scattering coefficient of bone tissues on the trajectory of pedicle screw placement using near-infrared spectroscopy. J Biomed Opt. 2014;19(11):117002.

41. Li W, Liu Y, Qian Z. Determination of detection depth of optical probe in pedicle screw measurement device. Biomed Eng Online. 2014;13:148.

42. Frank EH, Chamberland DL. An endoscopic pedicle probe: preliminary development. Neurolog Res. 1997;19(6):657661.

43. Frank EH. The use of small malleable endoscopes to assess pedicle screw placement: technical note. Minimally Invasive Neurosurg: MIN. 1998;41(1):10-12.

44. Joh JY, Choi G, Kong BJ, Park HS, Lee SH, Chang $\mathrm{SH}$. Comparative study of neck pain in relation to increase of cervical epidural pressure during percutaneous endoscopic lumbar discectomy. Spine (Phila Pa 1976). 2009;34(19):20332038.

45. Bolger C, Carozzo C, Roger T, McEvoy L, Nagaria J, Vanacker $\mathrm{G}$, et al. A preliminary study of reliability of impedance measurement to detect iatrogenic initial pedicle perforation (in the porcine model). Eur Spine J. 2006;15(3):316-320.

46. de Blas G, Burgos J, Regidor I, Barrios C, Sola R, Garcia-Urquiza S, et al. Recording diffusion responses from contralateral intercostal muscles after stimulus-triggered electromyography: refining a tool for the assessment of thoracic pedicle screw placement in an experimental porcine model. Spine (Phila Pa 1976). 2009;34(11):E391-E396.

47. Fekete TF, Kleinstuck FS, Mannion AF, Kendik ZS, Jeszenszky DJ. Prospective study of the effect of pedicle screw placement on development of the immature vertebra in an in vivo porcine model. Eur Spine J. 2011;20(11):1892-1898.

48. Le Cann S, Cachon T, Viguier E, et al. Influence of age and localisation on pedicle fixation in immature porcine spines.Comput Methods Biomech Biomed Eng. 2014;17(Suppl 1):66-67.

49. Lewis SJ, Lenke LG, Raynor B, Long J, Bridwell KH, Padberg A. Triggered electromyographic threshold for accuracy of thoracic pedicle screw placement in a porcine model. Spine. 2001;26(22):2485-2489; discussion 2490.

50. Lysack JT, Yen D, Dumas GA. In vitro flexibility of an experimental pedicle screw and plate instrumentation system on the porcine lumbar spine. Med Eng Phys. 2000;22(7):461-468.

51. Tan CE, Fok MW, Luk KD, Cheung KM. Insertional torque and pullout strength of pedicle screws with or without repositioning: a porcine study. J Orthop Surg. 2014;22(2):224-227.

52. Xue Q, Li H, Zou X, et al. Alendronate treatment improves bone-pedicle screw interface fixation in posterior lateral spine fusion: an experimental study in a porcine model. Int Orthop. 2010;34(3):447-451.

53. Yazici M, Pekmezci M, Cil A, Alanay A, Acaroglu E, Oner FC. The effect of pedicle expansion on pedicle morphology and biomechanical stability in the immature porcine spine. Spine. 2006;31(22):E826-E829.

54. Allen J, Akpolat YT, Kishan S, Peppers T, Asgarzadie F, Cheng WK. Comparison between gearshift and drill techniques for pedicle screw placement by resident surgeons. Int J Spine Surg. 2015;9:23.

\section{APPENDIX}

Supplemental Video 1. (A) Endoscopic pedicle inspection. The scope advances through the cannula. The internal aspect of the pedicle is visible (http://www.ijssurgery.com/lookup/suppl/doi:10. 14444/5030/-/DC1/videola.mp4). (B) Endoscopic pedicle inspection of an intact pedicle (http://www. ijssurgery.com/lookup/suppl/doi:10.14444/5030/-/ DC1/video1b.mp4).

Supplemental Video 2. (A) Endoscopic view of a medial pedicle wall breach. The video starts with the scope inside of the breach and immersed in epidural fat. The scope is then withdrawn and the defect is visible (http://www.ijssurgery.com/lookup/suppl/doi: 10.14444/5030/-/DC1/video2a.mp4). (B) Endoscopic view of a medial pedicle wall breach with a 30 -degree endoscope. The endoscope offers a more direct inspection of each wall (http://www.ijssurgery.com/ lookup/suppl/doi:10.14444/5030/-/DC1/video2b. mp4).

Supplemental Video 3. Endoscopic view of anterior pedicle breach (http://www.ijssurgery.com/ lookup/suppl/doi:10.14444/5030/-/DC1/video3. mp4). 
Supplemental Video 4. (A) Endoscopic view of lateral pedicle wall breach. The scope is introduced into the cannula. At 00:07, the paraspinous muscles are visible. The scope is withdrawn (http://www.ijs surgery.com/lookup/suppl/doi:10.14444/5030/-/ DC1/video4a.mp4). (B) Endoscopic view of lateral pedicle wall breach with 30-degree scope (http:// www.ijssurgery.com/lookup/suppl/doi:10.14444/ 5030/-/DC1/video4b.mp4).

Supplemental Video 5. Endoscopic guided balltip probe inspection of the pedicle. The ball-tip probe is located at the medial defect of the pedicle. The epidural fat is visible with the endoscope. At 00:24 the ball is passed out of the pedicle into the spinal canal. The shaft of the probe is visible adjacent to the epidural fat (http://www.ijssurgery.com/lookup/ suppl/doi:10.14444/5030/-/DC1/video5.mp4).

Supplemental Video 6. Endoscopic placement inspection of guidewire position. The guidewire is inserted in the anterior defect under careful guidance (http://www.ijssurgery.com/lookup/suppl/doi: 10.14444/5030/-/DC1/video6.mp4).

Supplemental Video 7. Endoscopic view of a pedicle with 2 divergent paths. One path is at approximately 2 o'clock and one path is at 7 o'clock (http://www.ijssurgery.com/lookup/suppl/doi:10. 14444/5030/-/DC1/video7.mp4).

Supplemental Video 8. (A) Endoscopic view of a pedicle with intact walls. At 00:01 the irrigation was ceased. Blood flow immediately resumed. At 00:15 irrigation was resumed. The blood was quickly flushed out and the pedicle cleared (http://www.ijs surgery.com/lookup/suppl/doi:10.14444/5030/-/ DC1/video8a.mp4). (B) Endoscopic view of a pedicle with intact walls. The irrigation was ceased at 00 : 01. Blood flow immediately resumed. At 00:29 irrigation was resumed. The blood was quickly flushed out and the pedicle cleared (http://www.ijssurgery. com/lookup/suppl/doi:10.14444/5030/-/DC1/vid eo8b.mp4).

Disclosures and COl: The study was sponsored by Orthopedic Sciences, Inc. One of the authors receives compensation in the form of royalties (K.R.). One of the authors is an employee of the company (J.B.). No compensation was provided for manuscript preparation.

Corresponding Author: Kristen Radcliff, MD, Department of Orthopedic Surgery, Thomas Jefferson University, Rothman Institute, 2500 English Creek Avenue, Egg Harbor, NJ 08234. Phone: (609) 573-3301; Email: radcliffk@gmail.com

Published 3 August 2018

This manuscript is generously published free of charge by ISASS, the International Society for the Advancement of Spine Surgery. Copyright (C) 2018 ISASS. To see more or order reprints or permissions, see http://ijssurgery.com. 